\title{
Competitive Strategies Among Elite Female \\ GYMNASTS: AN EXPLORATION OF THE RELATIVE \\ INFLUENCE OF PSYCHOLOGICAl SKILls TRAINING AND \\ NATURAL LEARNING EXPERIENCES
}

Clatire Calmels', Fabienne d'Arripe-Longueville 2.1 , Jean F. Fournier '3, and Amélie Soulard

IIInstitut National du Sport et de l'Éducation Physique, Paris, France

¿Université de Nice Sophia-Antipolis, France

${ }^{3}$ Université de Paris 10-Nanterre, France

'École de Psychologie, Université d'Ottawa, Ontario, Canada

\section{Abstract}

The purposes of this qualitative study were, (a) to compare the competitive strategies developed by national and international female gymnasts through natural learning experiences, (b) to compare the competitive strategies used by national gymnasts who benefited from a psychological skills training (PST) program to those developed by international gymnasts via natural learning experiences, and (c) to investigate the functions these strategies served in the two aforementioned cases. Individual in-depth interviews were conducted with three international and six national gymnasts. Three of the six national gymnasts followed a PST, whereas the other three did not. The international gymnasts never benefited from PST nether before nor duing the study. The resuls indicated that the strategies developed through natural experiences over time by the international gymnasts were widerand more elaborate than those of their national counterparts, but akin to those used by the national gymnasts who had benefited from a PST. The specific consequences of the characteristics of the international context and psychological skills training on the strategies gymnasts elaborated were also highlighted. Results are discussed relative to research on deliberate practice and sport talent development (Ericsson, Krampe, \& Tesch-Romer. 1993).

Key Words: competitive strategies, elite gymnasts, psychological skills training, natural learning experience

Correspondence concerning this article should be addressed to Claire Calmels, Laboratoire de Psychologie du Sport. Paris. E-mail: ccalmels@hotmail or 
It is always disconcerting and frustrating to note that certain athletes perform better during an event than others who are more physically talented, and that some athletes perform brilliantly during practice and less well in competition. Coaches and athletes generally agree that mental states often explain the differences observed in competitive performance. Based on investigations of the psychological characteristics and the strategies used by high level performers, many studies in sport psychology literature have examined the attributes associated with athletic success. Two kinds of research can be identified, depending on the methodological approach adopted, quantitative or qualitative. In research based on quantitative methods the influence of the athletes' personal characteristics (e g. age, levelo instance, successful athletes have been characterized by a higher level of commitment motivation, self-confidence, more positive self-talk, more daily thoughts and dreams related to their sport, superior concentration skills, and fewer thoughts of failure than their less successful counterparts (see Williams \& Krane, 1998 for a review). Such athletes were also found to be better able to cope with competitive mistakes (Mahoney \& Avener, 1977), and to manage competitive anxiety efficiently (Hanton \& Jones, 1999). More recently, Thomas, Murphy, and Hardy (1999) reported that compared to athletes of a lower standard, international athletes used more psychological skils in training and had more vared competitive strategies. Furthermore, older performers reported less use of imagery and activation strategies, in competition or in practice, better use of emotional control strategies. in practice, and more automaticity, in competition, than their younger counterparts.

To get a deeper understanding of elite athletes' experiences, and since there are very few high-level performers, other investigations have tended to turn to a qualitative interview approach (Patton, 1990). Thus, the psychological skills used by elite athletes in favorable situations have been explored through the recall of the best-ever performance (e.g. Cohn 1991; Hollander 8 A 2000). The flow experience (e.g. Jackson, 1992) has also been described. Other studies have investigated the sources of stress (e.g., Scanlan, Stein, \& Ravizza, 1991), or the difficulties faced by elite athletes (e.g., Jackson, Dover, \& Mayocchi, 1998). Finally, some research has compared the mental strategies used by successful and unsuccessful athletes (e.g., Orlick \& Partington, 1988), expert and novice athletes (McPherson, 2000), in their best and worst matches (e.g. . Gould, Eklund, \& Jackson, 1992a, 1992b). The information collected through in-depth interviews is broadly in line with the results of quantitative studies (see Gould, Guinan Greenleaf, Medbery, \& Peterson, 1999, for areview). Overall the results stress thathighteve performance requires common psychological skills, such as rational thinking, mental readiness, use of a competitive routine and plan, high levels of motivation, commitment, concentration, self-confidence, goal-setting skills, skills for dealing with distractions and unexpected events, the ability to regulate arousal, to control performance imagery, and a degree of automaticity in coping strategies.

While the favorable role of mental skills on expert performance in sport is now well documented, little is known about how these successful skills are acquired and developed. acquire and developmentalskills: educationalint training programs (Vealey, 1994; Weinberg \& Comar, 1994), and natural learning experiences (Gould, Dieffenbach, \& Moffet, 2002; Hanton \& Jones, 1999; Weiss, 1991). In the case of psychological skills training (PST), intervention programs are offered to athletes by applied sport consultants. These PST programs are generally aimed at helping athletes acquire and strengthen mental skills to improve sport performance and generate a positive approach to the competitions. The techniques most used include goal setting, relaxation, arousal regulation, imagery, and thought control (self-talk and affirmation) (e.g., Defrancesco \& Burk, 1997; Gould, Tammen, Murphy, \& May, 1989; Taylor, 1995). Numerous studies have reported the favorable effects of psychological skills training programs on competitive performance le g. Cogan \& Petrie, 1995. Garza \& Feltz 1998: Grovios, 1992: Kendall Hrycaiko Martin, \& Kendall 1990, LiWei, QiWei, Orlick, \& Zitzelsberger, 1992), and on particular \& Kendal, psychological indexessuch as states of somatic and cognitive anxiety (Bakker \& Kayser, 1994; Cogan \& Petrie, 1995; Tery, Mayer, \& Howe, 1998), self-confidence (Bakker \& Kayser, 1994; Garza \& Feltz, 1998; Temy, Mayer, \& Howe, 1998), imagery ability (Rodgers, Hall, \& Buckolz, 1991), and team cohesion (Savoy, 1997).

Furthermore, psychological skills appear to develop through natural learning experiences and social influences. Based on her involvement with children and adolescents practicing appropriate practice appropriate pracice meds, coach's and parents' behaviors, feedback and reinforcement, and peer modeling) might enhance psychological skills such as self-perception, intrinsic motivation, positive attitude, enjoyment, skills for coping with anxiety, and sportsmanship. More recently, d'Arripe-Longueville, Fournier, and Dubois (1998) found that, within the particular French judo system, tough coaching styles were responsible for building mental skills, such as athletes' commitment and development of a "winning spirit." This study also outlined that elite judo athletes were highly self-determined, and had developed their own coping strategies that helped them overide the often unpleasant attitudes of the coaches, and cow how elite and developed efrective cognitive skills and strategies that enabled them to interpret pre-competitive anxiety as facilitative for performance. They reported that this acquisition had been elaborated over time through natural learning experiences. This process, unfolding throughout the swimmer's career, was composed of different components such as listening to parents, coaches, and more experienced competitors, taking their advice into account, and performing at different competitive standards and against different opponents. Very recently, Gould et al. (2002) confirmed the importance of the social background (i.e. family, coach, and exposure to elite athlete models) in the development of talentin elite athletes. Forinstance, Gould reported that being exposed at an early age to high-level competitors in the same discipline was one factor among others, which "provided both inspiration and various forms of vicarious learning" (Gould, 2001, p. 58).

On the whole, these studies suggest that some elite athletes acquire and develop successful mental skills over the years through various experiences and social influences, without any involvement in an educational psychological skills training program. They also suggest that athletes need to engage actively in this development The concept of delberatepractice (a) Tesch-Romer, 1993) illustrates this long and high engagement. 
Because the influence of these "natural" learning experiences (i.e., without any structured PST) on the development of psychological skills has not been frequently explored in the sport psychology literature, several issues deserve further investigation. First, in order to extend Hanton and Jones's (1999) study, which only focused on pre-competitive anxiety, it would be of interest to consider all the mental skills and strategies used by athletes during competitions. Furthermore, because previous research mainly concerned adults, the question of the applicability of the results to younger participants is raised. In fact, young athletes might not possess enough maturity to develop, without the help of an educational intervention (PST), the same kind of competitive skills and strategies as their older counterparts.

Therefore, the purpose of the present study was threefold. First, to compare the competitive strategies developed by national and international gymnasts through natural learning experiences. The term strategies designates the procedures used by the athletes to develop mental skills (Vealey, 1988). Second, to compare the competitive strategies developed by national female gymnasts who benefited from a PST to the strategies developed by international athletes through natural learning experiences. Third to understand through a careful investigation the reasons for the use of each strategy (i.e., what functions these strategies served) in the two aforementioned cases. Because these investigations were exploratory in nature, no a priori hypotheses were offered. The discipline of gymnastics was chosen because of its competitive environment which is demanding (e.g., requirement of a display of diverse skills, no right to make a mistake, risk of injury, evaluations by others), and therefore requires the use of strategies.

\section{METHOD}

\section{PARTICIPANTS}

The participants were nine French elite female gymnasts aged 12 at the time of the study. None of these participants had any previous experience in psychological skills training before the beginning of the study. All gymnasts had 25 hours of physical training per week and had regularly participated in national competitions. Three of these gymnasts, ranked between the $1 s t$ and $3 r d$ places. They were selected for international tournaments and were preparing for the European junior championships in 2002. The six other gymnasts were ranked between 10th and 20th. Among these six athletes, three followed a PST program, whereas the other three did not benefit from this program. We therefore distinguished three categories of participants. The first was composed of international gymnasts $(N=3)$ with physical training, the second of national gymnasts ( $N=3$ ) with physical training, and the third of national gymnasts $(\mathrm{N}=3$ ) with physical training and PST. To guarantee anonymity, a coding system was used to identify the participants. International and national gymnasts with physical training were identified as International and National participants with Natural Learning with PST program were attributed NPST initials.
PROCEDURE

The procedure involved two stages: (a) a ten-month PST program and (b) in depth-interviews.

\section{PST program}

In addition to their physical training, three national gymnasts from sport center $X$ followed a 10-month PST program at a rate of half an hour per week. This program involved five stages: relaxation ( 8 sessions), self-talk ( 5 sessions), goal setting ( 3 sessions), focusing (4 sessions), and visualization (5 sessions) (see Appendix). This psychological skills training was supervised by a consultant who had a rich background in gymnastics and in sport counseling. The other six gymnasts (three nationals and three internationals) from sport center $Y$ did not benefit from this psychological skills training: they only trained physically. The fact that the participants belonged to two different sport centers avoided any risk of "experimental contamination," such as exchange of information between the participants. Even though the procedure had shortcoming (i.e. shortcoming (i.e. imperfectequivalence between the national participants), all the athletes limate followed the same patterns.

\section{In depth-interviews}

In depth-interviews were undertaken with the nine gymnasts. The parents of the athletes gave written consent prior to study procedures. At the beginning of each interview, the investigator explained the purpose of the study and the format of the interview to the participants, and asked permission to make an audio recording of the interview. Information about the participant's age and background (e.g., when they began gymnastics, if they belong to a club, how many hours they train) was collected. Confidential retrospective interviews, ranging in duration from 60 minutes to 100 minutes, were then conducted. To make the gymnasts feel at ease and trust the inteniewer, a neutral site was chosen: a lecture room outside the gymnasium.

The interviewer followed a structured interview guide composed of two parts. In the first part, the interviewer asked the gymnast to consider the major stages of her career and to think for a few minutes about her best competition. The gymnast was then invited to give general information about this event (i.e., where, when, and with whom it occurred) and to explain why she considered this event was her "best" competition. In the second part, the gymnast was asked to identify the strategies she had used during this competition and to explain her recall and describe her activity during this event chronologically and in details. To help the participant reconstruct her experience accurately, Rubin and Rubin's (1995) guidelines for indepth interviews were followed. Three types of questions were used: main questions, probe questions, and follow-up questions. The main questions consisted of asking the participant to describe her activity before, during, and after the competition. The probe questions allowed the interviewer to have a better understanding and to enrich the gymnasts' answers. For instance, questions about specific behaviors, thoughts, emotions, communication with the coach or the family were systematically asked to identify the strategies the participant had used during the event. Finally, follow-up questions were asked to get information about the reasons 
for using the strategies (i.e., the functions). When a function was mentioned, new issues in the participants' responses were explored. In many cases, the questioning began in an openended way and became increasingly focused and even directive because the participants were too young and had difficulty in verbalizing their behaviors and thoughts. Moreover, the topics to be covered (relaxation, activation, imagery, self-talk, communication/isolation, preparatory behaviors, planning, and assessment of the event) were listed in the interview guide but the interviewer adapted to the gymnast's point of view. The final part consisted in thanking the participants for having spared the time for the study, and in making an appointment to check the researchers' transcripts and interpretations of the interviews.

\section{INTERVIEWER}

The interviews were conducted by a female researcher with a Ph.D. in exercise and sport psychology. The interviewer was experienced in qualitative methods, had 15 years of experience as a gymnast and as a coach, and seven years of experience in sport psychology consultancy.

\section{DATA ANALYSIS}

The data was transcribed from the audio tapes to 130 single-spaced pages with a margin of $6 \mathrm{~cm}$ on the right side for coding the quotes. Three investigators, trained in qualitative methods, were involved in the data analysis process. Two investigators read each interview transcript carefully and the third investigator, considered as a "disinterested peer" (Lincoln \& Guba, 1985, p. 308), was asked to check the relevance of the categorization process. The first investigator, who conducted the interviews, listened to all the tape-recorded interviews to check if the re-transcription corresponded to what the gymnasts said, and to gather additional information, such as the tone of voice, the pauses, and the laughter. The other two investigators were deliberately kept in the dark as to the goal of the study.

After the reading stage, the interviews were analyzed using the procedures inspired by grounded theory principles (Strauss \& Corbin, 1990). First, the interview transcripts were divided into meaningful pieces of information called meaning units (MU). Second, MU were compared and grouped together according to common features into increasingly more complex categories (Tesch, 1990). Finally, the last step of the analysis consisted of identifying categories of similarities and differences between the NNLE and INLE gymnasts and between NPST and INLE gymnasts. Frequency counts were notreported becausethey were notdeemed relevant to the characterization of the effectiveness of of the relatively small sample.

\section{Credibility}

In this study, credibility was achieved in four ways (Lincoln \& Guba, 1985). First, investigator triangulation consisted of independent coding of the data, comparison, and discussion of the codes until a consensus was reached. Second, six of the participants verified the researchers' scripts and interpretations of the interviews to make sure that the information collected was authentic. Third, one expert researcher in qualitative research was asked to check the relevance of the categorization process. Finally, gymnasts were observed in various settings such as training sessions and competitions to enhance the methodological rigor by providing the researchers with a deeper understanding of the participants' behaviors.

\section{DEPENDABILITY}

According to Lincoln and Guba (1985), several procedures were respected to establish dependability. The two investigators were trained in qualitative research by an expert on the subject: Methodological and data analysis procedures were described in depth, and pilotinterviews were conducted with former elite performers, who had participated either in the Olympic Games or in the World Championships. Additionally, one of the investigators had good knowledge of gymnastics, while the other two were deliberately unaware of the purpose of the study. This last choice was made to control an eventual bias in the interpretation of the data.

\section{RESULTS}

The nine interview transcripts were analyzed on a line-by-line basis by two coders who reached consensus that there were $55 \mathrm{MU}$ for the three NNLE participants, $73 \mathrm{MU}$ for the three INLE participants, and $81 \mathrm{MU}$ for the three NPST participants. MU were then assembled into categories that were named according to the common features their MU shared. These categories described the strategies used by the gymnasts. A final level of analysis consisted of identifying the main functions of the strategies, and of organizing them into major categories. Thus, for the NNLE gymnasts, the $55 \mathrm{MU}$ were abstracted into 23 categories and 7 major categories. For the INLE athletes, the $73 \mathrm{MU}$ were assembled together to make up 41 categories and 8 major categories; and for the NPST group, the $81 \mathrm{MU}$ coalesced into 35 categories and 7 major categories. Table 1 reports the major categories and categories that emerged from the analysis for each group. The results are presented in two parts: (a) the comparison of the strategies used by the NNLE and INLE gymnasts, and (b) the comparison of the strategies employed by the NPST and INLE gymnasts.

\section{COMPARISON OF THE STRATEGIES USED by THE NNLE AND INLE GYMNASTS}

The findings of the content analysis revealed similarities and differences in the type and function of the strategies used by the NNLEand INLE gymnasts (see Table 1). 
Table 1

Gymnasts' strategies and their perceived functions

\begin{tabular}{|c|c|c|c|}
\hline $\begin{array}{l}\text { Function of } \\
\text { the strategies }\end{array}$ & NNLE Strategies & INLEStrategies & NPST Strategies \\
\hline $\begin{array}{l}\text { Decrease } \\
\text { anxiety }\end{array}$ & $\begin{array}{l}\text { Breathing slowly and deeply } \\
\text { Giving social support to their } \\
\text { peers } \\
\text { Imagery }\end{array}$ & $\begin{array}{l}\text { Breathing slowly and deeply } \\
\text { Giving social support to their peers } \\
\text { Self-talk } \\
\text { Imagery } \\
\text { Transformation of the moves }\end{array}$ & $\begin{array}{l}\text { Breathing slowly and deeply } \\
\text { Giving social support to their peers } \\
\text { Self-talk } \\
\text { Establishment of landmarks }\end{array}$ \\
\hline $\begin{array}{l}\text { Decrease fear } \\
\text { of injury }\end{array}$ & $\begin{array}{l}\text { Imagery } \\
\text { Self-talk } \\
\text { Preparatory movements }\end{array}$ & $\begin{array}{l}\text { Imagery } \\
\text { Warming-up efficiently }\end{array}$ & \\
\hline Accept pain & & $\begin{array}{l}\text { Imagery } \\
\text { Self-talk }\end{array}$ & \\
\hline \multirow{2}{*}{$\begin{array}{l}\text { Increase } \\
\text { activation }\end{array}$} & Self-talk & Self-talk & Self-talk \\
\hline & Jumps & $\begin{array}{l}\text { Hyperventilation } \\
\text { Slaps } \\
\text { Breathing associated with self-talk }\end{array}$ & \\
\hline \multicolumn{4}{|c|}{ Stereotyped behavior coupled with self-talk } \\
\hline $\begin{array}{l}\text { Decrease } \\
\text { activation }\end{array}$ & & & $\begin{array}{l}\text { Breathing slowly and deeply } \\
\text { Stereotyped behavior coupled with } \\
\text { breathing }\end{array}$ \\
\hline $\begin{array}{l}\text { Increase } \\
\text { engagement }\end{array}$ & Imagery & $\begin{array}{l}\text { Imagery } \\
\text { Self-talk } \\
\text { Breathing associated with self-talk } \\
\text { Looking at the competitors' routines } \\
\text { Slaps } \\
\text { Glance towards the family } \\
\text { Comparison of hermarks to those } \\
\text { of her directopponent }\end{array}$ & $\begin{array}{l}\text { Breathing associated with self-talk } \\
\text { Looking at the competitors' routines }\end{array}$ \\
\hline \multirow[t]{2}{*}{$\begin{array}{l}\text { Maintain } \\
\text { attentional } \\
\text { focus }\end{array}$} & $\begin{array}{l}\text { Self-talk } \\
\text { Imagery } \\
\text { Isolation }\end{array}$ & $\begin{array}{l}\text { Self-talk } \\
\text { Imagery } \\
\text { Isolation }\end{array}$ & $\begin{array}{l}\text { Self-talk } \\
\text { Imagery }\end{array}$ \\
\hline & Thought stoppage & Preparatory movements & $\begin{array}{l}\text { Thought stoppage } \\
\text { Imagery associated with self-talk } \\
\text { Looking at the judges }\end{array}$ \\
\hline \multirow[t]{2}{*}{$\begin{array}{l}\text { Increase self } \\
\text { confidence }\end{array}$} & $\begin{array}{l}\text { Self-talk } \\
\text { Imagery } \\
\text { Simulation of movement } \\
\text { Lookingforcoachencouragement }\end{array}$ & $\begin{array}{l}\text { Self-talk } \\
\text { Imagery } \\
\text { Simulation of movement } \\
\text { Looking for coach's encouragement } \\
\text { and congratulation }\end{array}$ & $\begin{array}{l}\text { Self-talk } \\
\text { Imagery } \\
\text { Looking for coach encouragement and } \\
\text { congratulation }\end{array}$ \\
\hline & Avoidinglooking at thejudges & $\begin{array}{l}\text { Thought stoppage } \\
\text { Preparatory movements } \\
\text { Simulation of movement combined } \\
\text { with self-talk } \\
\text { Rehearsal of strategies that were } \\
\text { efficient in training sessions }\end{array}$ & $\begin{array}{l}\text { Simulation of movement associated with } \\
\text { self-talk } \\
\text { Rehearsal of strategies that were } \\
\text { efficient in training sessions } \\
\text { Stereotyped behavior } \\
\text { Check of apparatus characteristics } \\
\text { Looking for an acquaintance among the } \\
\text { judges }\end{array}$ \\
\hline
\end{tabular}

\begin{tabular}{|c|c|c|c|}
\hline $\begin{array}{l}\text { Function of } \\
\text { the strategies }\end{array}$ & NNLEStrategies & INLE Strategies & NPST Strategies \\
\hline $\begin{array}{l}\text { Lookfor } \\
\text { excellent } \\
\text { performance }\end{array}$ & $\begin{array}{l}\text { Self-talk } \\
\text { Imagery } \\
\text { Listening to the coach's } \\
\text { technical advice } \\
\text { Preparatory movements to } \\
\text { reduce the warming-up } \\
\text { decrement } \\
\text { Imagery associated with self- } \\
\text { talk }\end{array}$ & $\begin{array}{l}\text { Self-talk } \\
\text { Imagery } \\
\text { Listening to the coach's technical } \\
\text { advice } \\
\text { Preparatory movements to reduce } \\
\text { the warming-up decrement } \\
\text { Charming the judges to get a good } \\
\text { mark } \\
\text { Simulation of movement associated } \\
\text { with self-talk } \\
\text { Setting self-referenced goals \& } \\
\text { checcingtheirfulfillment } \\
\text { Warming-up fficiently } \\
\text { Self-assessment at the end of the } \\
\text { competitive routine and the event }\end{array}$ & $\begin{array}{l}\text { Self-talk } \\
\text { Imagery } \\
\text { Listening to the coach's technical advice } \\
\text { Preparatory movements to reduce the } \\
\text { warming-up decrement } \\
\text { Charming the judges to get a good } \\
\text { mark } \\
\text { Simulation of movement } \\
\text { Setting self-referenced goals } \\
\text { Warming-up efficiently } \\
\text { Self-assessment at the end of the } \\
\text { compeititive routines and at the end of } \\
\text { the event } \\
\text { Establishment of landmarks } \\
\text { Adaptation to comperitive apparatus } \\
\text { Breathing associated with imagery }\end{array}$ \\
\hline
\end{tabular}

Similarities in the type and function of the competitive strategies used by the NNLE and the INLE gymnasts

Eight strategies have been identified as being used both by the NNLE and INLE gymnasts: breathing, isolation, simulation of movement, listening to the coach's advice, looking for the coach's encouragement and congratulations, giving social support to their peers, imagery, and self-talk. The functions of these strategies were similar in the two groups. (a) breathing slowly and deeply allowed the gymnasts to reduce anxiety; (b) isolation, which consisted in distancing oneself from significant others, helped the gymnasts to maintain attentional focus: (c) the simulation of movement defined as miming the movement, allowed them to increase self-confidence, as illustrated by the following quote:

I did some twists at the same spot and also little moves, but that, but that helped me a bit. Well I felt like I was doing my tricks... Well I don't know, it helps a little bit, it gives me confidence (INLE 2):

(d) listening to the coach's technical advice was actively sought by NNLE and INLE gymnasts in order to stimulate their desire to excel; (e) looking for the coach's encouragement and congratulations helped the gymnasts enhance their self-confidence; (f) giving social support to their peers (observing teammates, chatting with them, encouraging them, and counseling them) allowed both groups to decrease anxiety. Moreover, imagery served to decrease anxiety, them) allowed both groups to decrease anxiety. Moreover, imagery served to decrease anxiety, decrease fear of injury, increase engagement, increase self-confidence, maintain attentional focus and, look for excellent performance. For example, one NNLE gymnast indicated, "I was
doing my routines again in my head....Er, it gave me confidence "(NNLE3), and (g) self-talk was reported by both groups of gymnasts to increase activation, increase self-confidence, maintain attentional focus, and lookfor excellent performance. 


\section{Differences in the type and/or function of the competitive strategies used by the NNLE} and INLE gymnasts

Four types of differences emerged: (a) differences in the type of strategies, (b) differences in the degree of elaboration of the strategies, (c) differences in the functions fulfilled by similar strategies, and (d) differences in the number of functions fulfilled by similar strategies.

Differences in the type of strategies. The following nine strategies were employed solely by the INLE gymnasts and were not identified among their national counterparts: looking at the competitors' routines, setting self-referenced goals and checking their fulfillment, rehearsal of strategies that were efficient in training sessions, transformation of the moves, warming-up efficiently, glancing towards the parents, charming the judges, self-assessment at the end of the competitive routine and the event, and comparison of the gymnast's own marks to thos of her direct opponent. (a) looking at the competitors' routines allowed INLEgymnasts to to do even better "

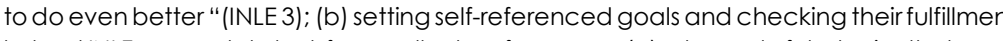
helped INLE gymnasts to look for excellent performance; (c) rehearsal of strategies that were efficient in training sessions helped the gymnasts increase their self-confidence; (d) the transformation of the moves was one solution found by an INLE gymnast to cope with anxiety. Either she emphasized them in the routine, or she speeded them up in the warm-up; (e) warming-up efficiently decreased one INLE gymnast's fear of injury, and enabled INLE gymnasts to use the short warm-up time efficiently. For example, as soon as the judges gave the starting signal, grmnasts rushed to the starting point to begin their warm-up in first position. (f) glancing towards the family allowed INLEgymnasts to increase their engagement. This was apparent in the following quote:, "After that I looked a bit my dad and my mum and they told me 'Go on, keep going,' and then, well, I was even more motivated "(INLE 1); (g) INLE gymnasts also displayed behavior to charm the judges (hairdo, smile, eye contact), while NNLE gymnasts avoided looking at the judges. After a brief eye contact, they stared at their papers. Moreover, INLE gymnasts carried out a self-assessment of their performance at the end of the competitive routine and event as shown below:

Well, I try to warm-up for my vault, and to try to see one more time in my head all have done, I keep that in my head, I follow his (coach) advice, and while I walk to while I go to my vault mark, er then I think again about what I've done, about his advice, and try to, to think about it globally, to put together everything I said, and everything he told me and I try to make a bettervault (INLE 1):

and finally, (i) the comparison of her own marks with those of her direct opponent was a means for one INLE to increase her engagement.

Differences in the degree of elaboration of the strategies. The degree of elaboration of the strategies (i.e., imagery and self-talk) used by the INLE gymnasts was higher than their national counterparts. Imagery used by INLE gymnasts was more elaborate, controlled, and vivid than the imagery of their national counterparts (see Figure 1). In fact, the majority of INLE participants was able to use a combination of internal and external imagery associated with kinesthetic modality, whereas NNLE gymnasts employed solely either external or internal perspective. INLE gymnasts were also able to visualize positive outcomes in color, while NNLE gymnasts visualized them in black and white, and from time to time with negative outcomes. For example, a NNLE gymnast said, "Well sometimes, I saw I was too far forward or I hit. I nearly hit my feet against the bar "(NNLE2).

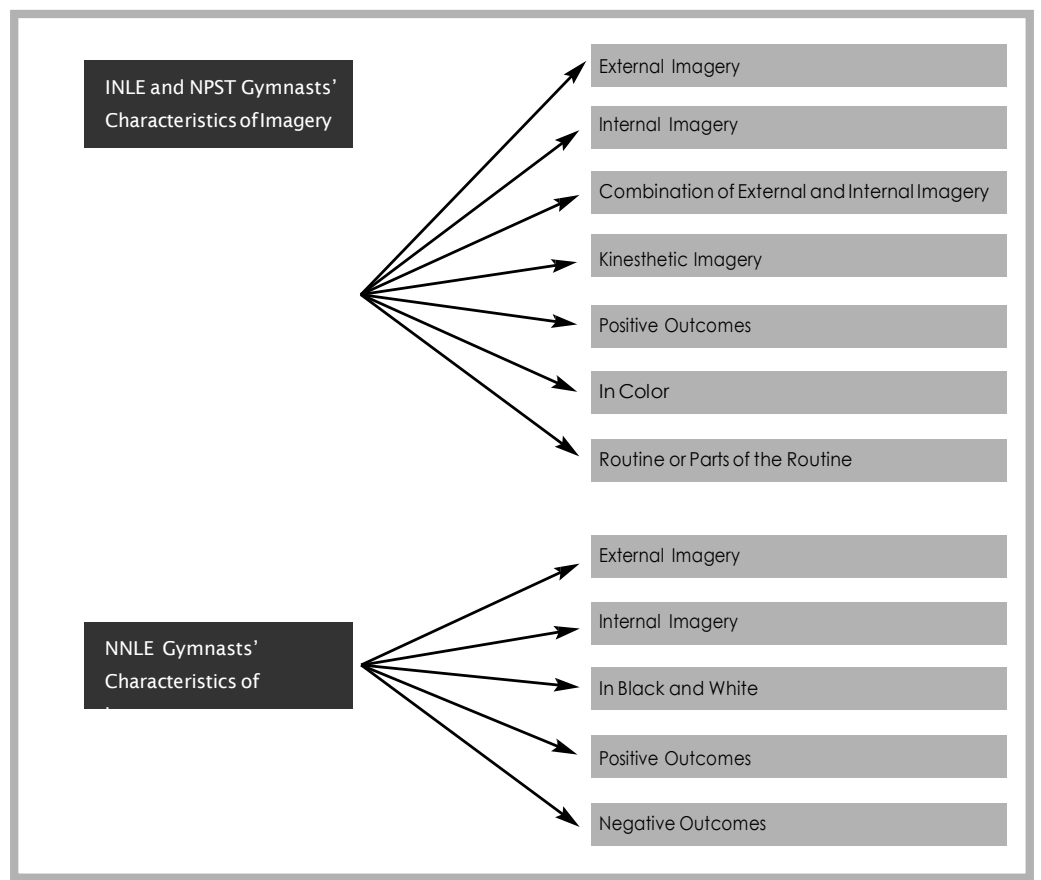

Figure 1. Hierarchical trees illustrating the characteristics of imagery used by INLE, NNLE, and NPST gymnasts.

The manner in which the INLE gymnasts talked to themselves was also more diversified (see Figure 2). Indeed, the nature of INLE gymnasts' thoughts consisted of (a) encouragement, (b) similarities with training, (c) technical advice, (d) psyching-up thoughts, (e) challenge, (f) obligation to compete and to engage, (g) self-efficacy beliefs, (h) emotional states, and (i) evaluative assessments. Conversely, NNLE gymnasts' self-talk content was restricted to three categories referring to (a) similarities with training. (b) technical advice, and (c) self-efficacy beliefs.

Furthermore, INLEgymnasts associated strategies together, in more varied ways than NNLE gymnasts did. INLE gymnasts combined self-talk with movement simulation to enhance selfconfidence and to look for excellent performance; they also associated breathing with self-talk to facilitate the implementation of activation and engagement. NNLE gymnasts only formed a combination of imagery and self-talk for the research of excellent performance. 


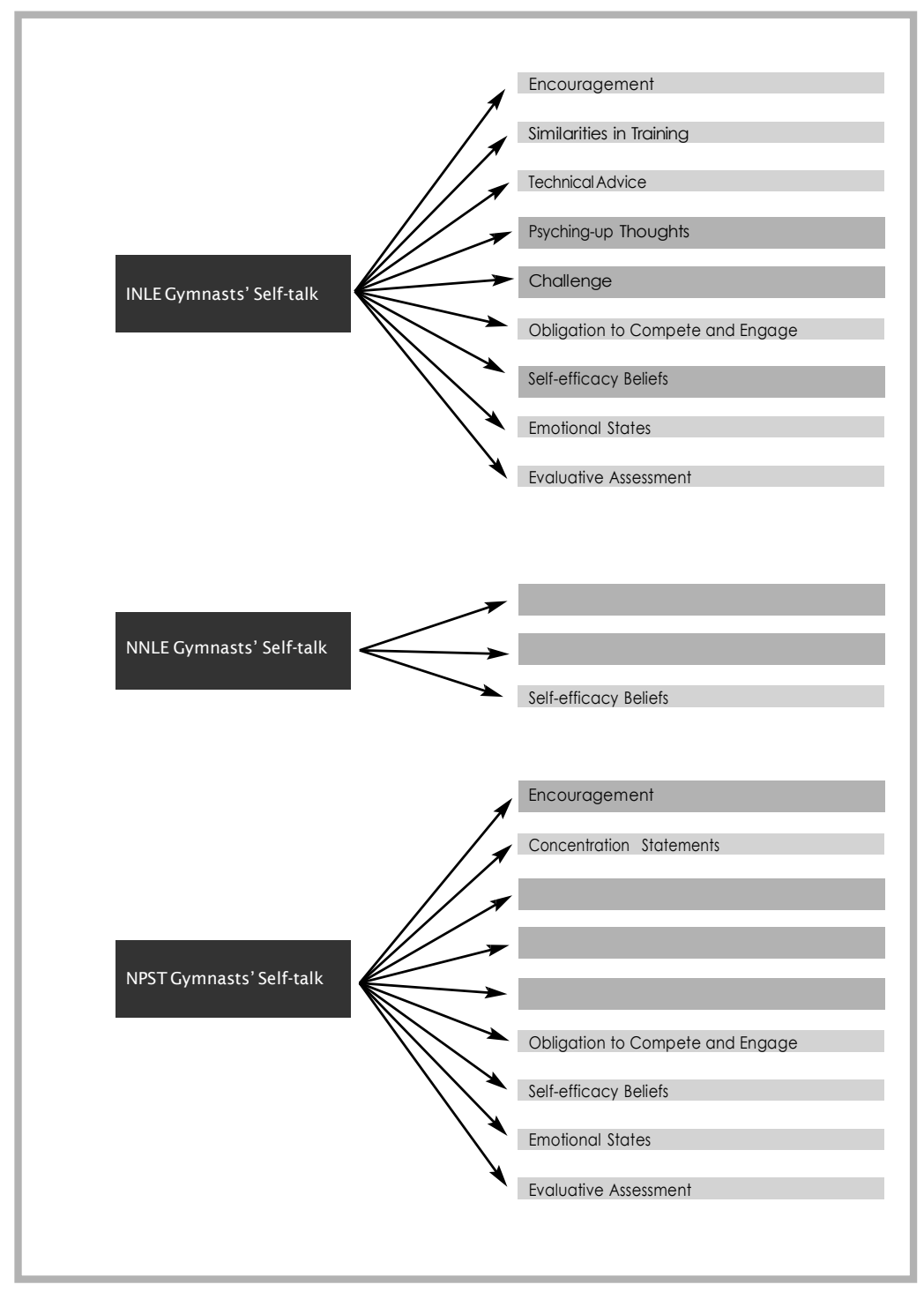

Figure 2. Hierarchical trees illustrating the nature of the self-talk used by INLE, NNLE, and NPST gymnasts.
Differences in the functions fulfilled by similar strategies. Two strategies (i.e., thought stoppage, and preparatory movements) were used independently by the NNLE and the INLE gymnasts to fulfill different functions. Thought stoppage enhanced self-confidence for INLE gymnasts, while this helped NNLE gymnasts maintain attentional focus. For example, one INLE gymnast stopped thinking about success and redirected this unproductive thought towards technical advice, and this helped her to be more self-confident, as is apparent in the quote below:

Between routines, l asked myself questions, l asked myself, 'Am I gonna do well? Am I'? Then, I told myself not to think about that and to remember what the coach tells me,

his advice and all that. (INLE 1)

Preparatory movements, which are the execution of movements to prepare the gymnast for doing her routine (e.g., simple movements, handstands, jumps), were used by the INLE gymnasts to maintain attentional focus, increase self-confidence, whereas NNLE did them to decrease the fear of injury.

Differences in the number of functions fulfilled by similar strategies. Some strategies (i.e., preparatory movements, imagery, and self-talk) were used by the INLE gymnasts to fulfill more functions than those of their national counterparts.

Preparatory movements were used by the INLE gymnasts to maintain attentional focus, increase self-confidence, and look for excellent performance, whereas NNLE used them to decrease the fear of injury and to look for an excellent performance. Though the two groups used imagery to serve common functions, imagery was also exclusively applied by INLE gymnasts to cope with pain. Because of the importance of particular competitions for their career, INLE gymnasts sometimes competed in spite of injury, and without informing their coach. Therefore in orderto forgettheirfeelings of pain theyvisualized theirroutine orpart of it Finaly, though self-talkwas used by both groups of gymasts to fulill com rou functions Of it. inaly, though NNLE gymnasts also employed self-talk for decreasing the fear of injury, whereas gymnasts used it for reducing anxiety, coping with pain, and increasing engagement.

COMPARISON OF THE STRATEGIES USED BY THE NPST AND THE INLE GYMNASTS

The findings of the content analysis revealed similarities and differences in the type and function of the strategies used by the NPST and INLE gymnasts (see Table 1).

\section{Similarities in the type and function of the NPST and INLE gymnasts}

Eleven strategies used both by the NPST and INLE gymnasts for fulfiling similar functions were identified: warming-up efficiently, listening to the coach's technical advice, looking for the coach's encouragement, looking at the competitors' routine, giving social support to one's peers, imagery, self-talk, preparatory movements, rehearsal of strategies that were efficient in training sessions, adapting behaviors to charm the judges, and self-assessment. (a) warmingup efficiently to manage the warm-up time constraints was sought to look for excellent performance. In order to manage the short warm-up time and to optimize its efficiency, as soon as the judges gave the signal to begin the warm-up, gymnasts rushed to the diagonal to execute, in the first place, their tumbling pass. The same scenario was observed for the vault: Gymnasts ran as quickly as possible to be the first at the starting point on the run way to 
execute their first acrobatic jump attempt in first position. Another example for the beam consisted, during the 30 second-warming-up, in doing the elements of the routine in a different order than the order planned in the routine. This re-organization helped the gymnast not to lose valuable time by moving needlessly forward and back; (b) listening to the coach's advice was perceived as a means to reach technical excellence; (c) looking for the coach's encouragement enhanced the gymnasts' self-confidence; (d) looking at the competitors' routines was sought by NPST and INLE gymnasts to increase their engagement. A gymnast said:

I was watching the girl performing, and also my opponents, it motivated me, er well let's say I see a girl with the same move, and she is doing well, well. I tell myself that I will have to do better (NPST 2):

(e) giving social support to their peers allowed the gymnasts to decrease their anxiety; (f) imagery was used in many similar ways by NPST and INLE gymnasts (see Figure 1). All the gymnasts visualized the routine, or part of it, in color and with positive outcomes. Some of them even used a combination of internal and external imagery associated with kinesthetic self-confidence, and look for excellent performance (see Table 1). The following example reflects the use of external imagery with a positive outcome for an element of the routine, with the aim of looking for an excellent performance:

To try to correct, to modify, well I do it with imagery. I would see myself from behind so that I would see the axis. It tells me what to do, how I should be. I shouldn'tlower my shoulder, got to jump properly (NPST3);

(g) for both groups, self-talk was perceived as a means to several ends, such as decreasing anxiety, increasing activation, maintaining attention focus, enhancing self-confidence, and looking for excellent performance; (h) preparatory movements allowed the two groups of gymnasts to look for excellent performance; (i) The rehearsal of strategies that were efficient in training sessions was repeated by NPST and INLE gymnasts to increase their self-confidence during the event; (j) adapting behaviors to charm the judges, such as hairdo, smile, and eye contact, constituted one of the means NPST and INLE gymnasts used to get a good mark; and finally, ( $k$ ) self-assessment was applied by INLEand NPST gymnasts for the purpose of looking forexcellentperformance. Atthe end of the competition they spotted theirmistakes, analyzed the reasons for having made them and developed solutions to be more successful in the following event.

\section{Differences in the type and/or functions of the competitive strategies used by the NPST}

\section{and INLE gymnasts}

Four types of differences emerged: (a) differences in the type of strategies, (b) differences in the degree of elaboration of the strategies, (c) differences in the functions fulfilled by similar strategies, and (d) differences in the number of functions fulfilled by similar strategies.

Differences in the type of strategies. Five strategies were employed solely by the INLE gymnasts, whereas six strategies were identified only among their NPST counterparts. As far as the INLE gymnasts were concerned, the transformation of the moves reduced anxiety; painstakingly going through the warm-up decreased the fear of injury; slaps enhanced activation and engagement; glancing towards the family increased engagement; and comparing one 's marks to those of one 's directopponent enhanced engagement.

With regard to the NPST gymnasts, looking for an acquaintance among the judges enhanced self-confidence, as reflectedin the following quote:

I looked to see who was part of the jury, to see if I knew, er to see if I knew someone, there was XX. It reassures me because I told myself, there, I know someone in the jury, er. they knowhow we work, and if we fall off, he knows how we usually compete (NPST2).

Looking at the judges also allowed one NPST gymnast to maintain her attentional focUs. NPST gymnasts displayed strategies of adaptation to competitive equipment to do an excellent performance. They added movements in their routine, they modified the technique of the acrobatic moves, and they even elaborated different technical advice according to the trademark of the apparatus. Checking the characteristics of the equipment increased NPST gymnasts' self-confidence. For this purpose, they checked that the equipment was set properly and that it was well adjusted. They also tested the intrinsic quality of the beam, such as its stability or its slipperiness, by performing easy moves. Stereotyped behavior also helped NPST gymnasts increase their self-confidence. Finally, the establishment of landmarks (visual and kinesthetic) had the function of decreasing anxiety and looking for excellent performance.

Differences in the degree of elaboration of the strategies. More than displaying behaviors to charm the judges, NPST gymnasts even calculated where to begin the routine in order to do the most outstanding part in front of the judges and to conceal its shortcomings. Despite a common behavior of self-assessment, what differs between the two groups is that INLE gymnasts systematically waited for their marks at the end of each competitive routine. One INLE gymnast's major concern was to know, after having executed her routine, if she scored higher than her most dangerous opponent. Whilst waiting for her mark, she analyzed her routine, calculated her departure mark, compared it with her opponent's, consideed her chances of being above herin the class and kept an eye on the electronic scoreboard that displayed her mark. Finally, the manner in which INLE and NPST gymnasts talked to themselves took common and different forms (see Figure 2). INLE and NPST gymnasts' similar thoughts consisted of, (a) encouragement, (b) technical advice, (c) challenge, (d) obligation to compete, (e) self-efficacy beliefs, ( $f$ ) emotional states, and ( $g$ ) evaluative assessment. Self-talk about psyching-up thoughts and similarities with training was used exclusively by INLE gymnasts, whereas self-talk focused on concentration statements and the recital of the components of the routine were only employed by NPST gymnasts.

Furthermore, NPST gymnasts associated strategies, in more varied ways than INLE gymnasts did, to complete multifarious goals. Indeed, gymnasts who received a training in mental preparation combined breathing with self-talk to increase engagement, imagery with self-talk to maintain attentional focus, simulation of movement with self-talk to enhance selfconfidence, stereotyped behavior with self-talk to enhance activation, stereotyped behavior with breathing to decrease activation, and breathing with imagery to look for excellent performance. 
In contrast, INLE gymnasts only associated self-talk with simulation of movement or breathing. The combination of self-talk with breathing was a way of increasing activation and engagement, whereas self-talk associated with a simulation of the movement served to enhance self-confidence and to look for excellent performance.

Differences in the functions fulfilled by similar strategies. Three strategies (i.e., breathing simulation of movement, and thought stoppage) were used independently by the NPST and the INLE gymnasts to fulfill different functions. First, breathing was one possible way of handling anxiety and activation. Taking a few deep breaths helped the two groups of grmnasts to decrease their anxiety. However, this strategy specifically helped NPST participants to reduce their activation, while taking deep and pumped-up breaths increased INLE gymnasts' activation. Second, the simulation of movements was perceived by the INLE gymnasts as a means of enhancing self-confidence, and for the NPST gymnasts as a means of reaching technical excellence. Examples of the two groups' strategies included the following:

By doing little moves that help me a bit... I feel that I am doing my tricks well I. Ithelps a little bit, it makes me more confident (INLE 1).

Infact, I was only miming It gives me the feelings I should have, good feelings, infact

the feelings I must normally get (NPST 3).

Finally, thought stoppage appeared to be one way of enhancing self-confidence for INLE gymnasts and of maintaining attentional focus for NPST gymnasts. For example, to get rid of mistake(s) made in the previous routine by replacing this thought with some productive thoughts (e.g., focus on technical advice, encouragement, looking at teammates) was perceived as efficient by NPST gymnasts to maintain attentional focus.

Differences in the number of functions fulfilled by similar strategies. First, preparatory movements allowed the two groups of gymnasts to look for excellent performance, while they were used to enhance self-confidence and maintain attentional focus by INLE gymnasts only. Second, as evidence from the INLE gymnasts' testimonies, imagery could also have other functions, such as decreasing anxiety, decreasing the fear of injury, increasing engagement, and coping with pain. Finally, among INLE gymnasts, self-talk could also have other functions, such as coping with pain and increasing engagement.

\section{Discussion}

The first purpose of the present study was to compare the competitive strategies developed by national and international gymnasts through natural learning experiences (i.e., without any participation in PST programs). Second, the study aimed at comparing the competitive strategies thathad been acquired by national female gymnasts who benefited from a PST with those developed by international athletes through natural learning experiences. Third, a careful investigation was made to understand why these strategies were used (i.e., what functions these strategies served) in the two aforementioned cases.
The comparison of data on the INLE and NNLE gymnasts revealed that these athletes used a panel of basic and similar strategies to fulfill similar functions. For instance, breathing slowly and deeply, imagery, and giving social support to their peers were strategies commonly used among the two groups to decrease anxiety. Imagery was also a shared strategy used to decrease fear of injury, increase engagement, maintain attentional focus, increase selfconfidence, and look for excellent performance. Finally, self-talk helped both kinds of gymnasts to increase activation, maintain attentional focus, increase self-confidence, and look for excellent performance. These strategies and the functions they fulfilled are well-known within the sport psychology literature and the coaching literature (e.g. Gould et al. 2002; Vealey, 1994; Weinberg \& Comar, 1994).

However, the findings also revealed several differences between INLE and NNLE gymnasts. First, INLE gymnasts set up strategies to cope with pain whereas their national counterparts did not. Elaborating strategies to deal with pain is unfortunately a widespread habit encountered among elite athletes who are used to competing even with injuries. The need to satisfy the coaches and the fear of losing their status as elite athletes could be put forward to explain their participation in an event with injuries, as already outlined by Krane, Greenleaf, and Snow (1997) in theirqualitativecasestudy of a formerelite gymnast Some of the verbalizationsof the INLE gymnasts suggest that they were afraid to inform their coaches about their pain, because the coaches would have taken out difficult moves from their routine, and this would have reduced their chances to integrate into the national team, and therefore, to take part in international competitions. They preferred quiet elaborate strategies, such as imagery and self-talk to overcome the pain. For instance, to forget the pain, they focused on things to do by visualizing their routine or part of it. This strategy, labeled dissociation in the classical literature pertaining to the cognitive control of pain (e.g., Masters \& Ogles, 1998), consists of ignoring strenuous physiological states. NNLE gymnasts were not worried by this type of problem, less was at stake in the situations they had to handle.

Most of the reasons mentioned by NNLE and INLE gymnasts for using self-talk and imagery were shared, and corroborate recent studies in the sport psychology literature on imagery (e.g., Jones \& Stuth, 1997; Martin, Moritz, \& Hall ,1999) and on self-talk (e.g., Hardy, Gammage, \& Hall, 2001). However, these strategies were also implemented for specific reasons by the two groups. For instance, INLE gymnasts used self-talk to decrease anxiety and increase engagement, whereas their national counterparts used it to decrease fear of iniury. This observation underlines the complex relationship between strategies and functions, as showninealierrearch (e.g. Ekund, Gould \& Jackson, 1993.Vergeer\&Hanrahan, 1998), and stresses the valdy of havingused anidisynctic procedure. In complexity of imagery and self-talk used by the INLE gymnasts was higher than that of their national counterpart. Specifically, INLE gymnasts used imagery in various forms (i.e., internal imagery, external imagery, kinesthetic modality, and auditory modality) by controlling, adapting, and combining every component of each strategy, while NNLE gymnasts did not. The use of kinesthetic imagery by INLE gymnasts and their report of well-developed imagery skills confirm earlier studies which have compared the use of imagery among successful and less successful athletes (e.g., Mahoney \& Avener, 1977). 
Along the same lines, INLE gymnasts' self-talk was also more diversified than that of their national counterparts. Specifically, though national and international gymnasts both used similar types of self-talk referring to technical advice, similarities with training, and self-efficacy beliefs, INLE gymnasts also mentioned using self-talk including encouragement, psyching-up thoughts, challenge, emotional states, and evaluative assessments. These characteristics are broadly consistent with those identified in the previous self-talk literature (e.g., Hardy et al., 2001; Rushall, 1984). For instance, Hardy and colleagues noticed that varsity athletes competing in various sports used mainly positive and negative self-talk, single cue words, phrases, or full sentences, and specific or general task instruction. Our findings add some interesting information to the self-talk literature by providing an accurate description of the type of self-talk used by national and international athletes.

Furthermore, the results showed that INLE gymnasts' social networks were more widespread than those of national gymnasts. Indeed, international gymnasts' social interaction strategies involved the coach, the family, the judges, and the competitors, whereas social relationships of their national counterparts only included the coach. Turning to the coach for encouragement, congratulations, and for technical advice was actively sought by all the gymnasts to increase their self-confidence and to reach an excellent performance. However, contrary to the national gymnasts, INLE gymnasts also glanced towards their family (parents and siblings) to enhance their engagement These results are consistent with previous findings which have shown that coaches ae the most cle whereas the paren whereas the par Richman, \& Hardy, 1989). Moreover, the posilive intuence of older siblings corroborales Côté's (1999) findings which showed that in some families, during the specializing years, this kind of influence was frequently observed. In addition, INLE gymnasts deliberately sought to charm the judges, whereas NNLE gymnasts avoided looking at them to increase their self-confidence. Consistent with this is the study by Duda and Gano-Overway(1996) which pointed out that young elite female gymnasts knew they were being watched by the judges and perceived this as a source of anxiety. On the otherhand, the INLEgymnasts deliberately faced the judges to influence their judgment positively. Smiling make-up, and eye contact were employed for that purpose. Finally, INEE Gymasts also looked at the competitors' routines, and one of them systematically compared her marks to those of her direct opponent. These attitudes based on social comparison were aimed at increasing engagement, as shown by Gould et al. (2002). These attitudes suggest that INLE gymnasts were ego-involved (Nicholls, 1989) in the competitive situation described. This is consistent with previous studies which found that elite athletes were more ego-oriented than people practicing sport at a lower standard (e.g., White \& Duda, 1994), and with qualitative inquiries in elite gymnastics (Krane etal., 1997).

Besides, the qualitative analysis of the interview transcripts also revealed that only INLE gymnasts were involved in a process of self-assessment of their performance. They set up selfreferenced goals, systematically checked whether their goals had been attained, self-assessed their performance at the end of the competitive routine and at the end of the event in order to self-regulate their performance. These findings substantiate previous research in other sports, such as professional golf (McCaffrey \& Orlick, 1989) and team sports (Dagrou, Gauvin, \& Halliwell, 1991). They are also consistent with the recent study by Gould et al. (2002) which pointed out that performance of experts was enhanced by what they called the "sport intelligence" and more specifically by their "ability to analyze."
To sum up, the comparison between INLE and NNLE gymnasts showed that the international gymnasts used a wider range and more elaborate strategies than those of their national counterparts. Specifically, INLE gymnasts' imagery and self-talk displayed a greater degree of complexity, their social networks were more widespread, and they also got involved in a process of self-assessment of their performance, whereas their national counterparts did not. These findings raise the question about the manner in which INLE gymnasts have developed these strategies without following a mental skill program. According to previous studies on mental skills development (Côté, 1999; Hanton \& Jones, 1999; Gould et al., 2002; Weiss, 1991) three types of factors could be put forward: (a) favorable social influences. (b) various parents, and teammates, might have helped the gymnasts to develop strategies to handle the competition efficiently. Second, it can be hypothesized that the opportunities offered to these international gymnasts (e.g., traveling abroad, meeting different people, experiencing new places, taking part in demanding and long periods of competition) allowed them to experience such proficient strategies. Third, it can be assumed that the international gymnasts engaged in deliberate practice (Ericsson et al., 1993). This would be consistent with the recent findings of Cumming and $\mathrm{Hall}(2000)$ who reported that the higher the level of expertise of an athlete, the more he/she had accumulated hours of deliberate imagery practice.

The competitive strategies used by INLE and NPST gymnasts were compared in the second stage of this study, and similarities in the type and function of the strategies were found. Most of the strategies reported involved the social environment of the athletes and more specifically the coach, the teammates, and the competitors. The relationships between the gymnasts and these significant others helped the athletes: (a) to increase their self-confidence when looking for the coach's encouragement, (b) to look for excellent performance when listening to the coach's technical advice, (c) to decrease their anxiety when giving social support, and (d) to increase theich environment personnel" to help elite athletes achieve a good performance.

The findings also revealed some differences between INLE and NPST gymnasts. First, INLE gymnasts set up strategies to decrease the fear of injury and to cope with pain, whereas the national gymnasts who benefited from a PST program did not. For that purpose, INLE gymnasts used imagery to reach both goals, while warming-up efficiently served to decrease fear of injury and self-talk to accept the pain. As pointed out by Magyar and Chase (1996), the fear of injury occurs when a gymnast is not confident in his/her ability to perform successfully in a taxing context. It can be hypothesized that thanks to the PST program, the NPST gymnasts were confident in their ability to execute their routine properly, and thus did not have to deal with the fear of injury. Indeed, as already outlined, NPST gymnasts did not fight to integrate into the national team to pursue an international career, whereas INLE gymnasts did.

Second, some strategies were used both by the INLE and the NPST gymnasts, but their content or the function the strategy served were different. For instance, one NPST gymnast's self-talk was made up of technical advice to maintain attentional focus, whereas her international counterpart's thoughts consisted of encouragement used to increase engagement. This can be 
explained by the multiple functions a strategy can serve (Rushall \& Lippman, 1998), and by the specific needs of each athlete and their personal cognitive styles (e.g., Madigan, Frey, \& Matlock, 1992). Third, NPST gymnasts combined strategies in a more complex way than their INLE counterparts. One can assume this may be due to the adhesion of the NPST gymnasts to the training program which included two specific sessions where thought stoppage was associated with self-talk. It can also be hypothesized that this involvement helped the gymnasts to develop other combinations of strategies, such as breathing with self-talk or imagery with self-talk. Finally, the results showed that only the NPST gymnasts used specific procedures to become familiar with the competitive equipment. Making slight and appropriate adjustments in their routine, checking the characteristics of the apparatusses and establishing landmarks made up the elements of this process. Although the content of the mental program did not specifically focus on the planning of an event, one can assume that the participation of the gymnasts in psychological skills training procedures could have favored cognitive processes such as planning, reasoning, analyzing, and anticipating (Orlick, 2000).

Taken together, these findings indicate that NPST and INLE gymnasts used a wide range of similar strategies, even if variations between the two groups of gymnasts in the content of some strategies could be ob and also demonstrated a panel of strategies to become familiar with the competitive environment, whereas theirinternational counterparts did not.

In conclusion, the present study suggests that international gymnasts have developed over time and used a set of more complex competitive strategies than their national counterparts. This development might be due to their sport experiences, to favorable social influences, and to deliberate practice (e.g., Ericsson etal., 1993; Gould etal., 2002). The findings also revealed that national gymnasts who benefited from a psychological skills training program were able to use strategies as complex as those used by international gymnasts. These findings point to un the fact that mental skills, developed through natural learning experiences by elite athletes, could be anticipated and learned via a psychological skills training program on condition the participants adhere to this intervention (BUll, 1991). Another interesting point is that NPST gymnasts appeared to build on the strategies they were taught (e.g., association of strategies or strategies to get familiarized with the competitive environment). Notwithstanding, it should be noted that some strategies used by international gymnasts to reduce fear of injury and accept the pain could not easily be taught to their national counterparts who did not have to deal with the same context and stakes.

It should be recognized that this study suffers from several important limitations. First, the sampling size in each group leads us to draw cautious conclusions. Second, concerns related to the retrospective nature of the interviews must be mentioned. Even if the experience of the gymnasts' best event was emotionally intense and significant to them, and thus easy to recall (Conway, 1990), limitations related to memory loss and thus the risk of giving a distorted version have to be considered or acknowledged. Methods approaching concurrent verbal reports and retrospective reports (e g. Von Cranach \& Harré 1982. Ericsson \& Simon 1993) ath he cocommended toreduce the efects of memory loss. The retrospective reports on all their thoughts and feelings during the preparation and the execution of their performance, as already done for the study of coach-athlete interaction (d'Arripe-Longueville, Saury, Fournier, \& Durand, 2001).

Another limitation comes from the nature of the event that was recalled: the best competition. Remembering only one event, which was different for each participant, might not have highlighted precisely all the strategies used by the gymnasts. The act of recalling more than one event, such as successful versus unsuccessful competitions, should also be investigated in the future. More research is therefore needed to identify the sources of development of elite athletes' competitive strategies and mental skills, and the relativeinfluence of significantothers in that development. Huture research could further exa the effectiveness of their competitive strategies and mental skills through deliberate practice.

Despite its limitations, this study presents important practical implications for coaches in charge of elite athletes. First, because mental skills seem to develop through sport experiences and the athlete' s social network, coaches should try to contribute to the creation of a positive environment. Tools such as the Ottawa Mental Skills Assessment Tool (OMSAT-3, DurandBush Salmela, \& Green-Demers, 2001) or the Test Of Performance Strategies (TOPS, Thomas et al. 1999), and in depth-interviews could allow the athletes to improve their awareness and understanding of the strategies they use. It would also enable the coaches to support them more efficiently by being aware of the types of social influences they react or are sensitive to, and by fostering positive peer interactions. Second, this study suggests that teaching mental skills appears to help coaches to speed up the process of getting athletes to the highest level and would help athletes to accomplish more. Despite these interests, sport psychology finds little recognition in the French culture, and national sport teams are slow in asking for such services. The close athlete-consultant relationship required to deliver psychological skills training often frightens coaches, who are afraid of losing power and control over their athletes. Implementing workshops for novice and expert coaches would help them trust psychological skills training interventions. 


\section{REFERENCES}

Bakker, F.C., \& Kayser, C.S. (1994). Effect of a self-help mental training programme. International Journal of Sport Psychology, 25, 158-175.

Bull, S.J. (1991). Personal and situational influences on adherence to mental skills training. Journal of Sport \& Exercise Psychology, 13, 121-132.

Cogan, K.D., \& Petrie, T.A. (1995). Sport consultation: An evaluation of a season-long intervention with female collegiate gymnasts. The Sport Psychologist, 9, 282-296.

Cohn, P.J. (1991). An exploratory study on peak performance in golf. The Sport Psychologist, $5,1-14$

Conway, M. (1990). Autobiographical memory: An introduction. Milton Keynes, PA: Open University Press.

Côté, J. (1999). The influence of the family in the development of talent in sport. The Sport Psychologist, 13, 395-417.

Cumming, J., \& Hall, C. (2000, October). Deliberate imagery practice. Paper presented at the Association for the Advancement of Applied Sport Psychology Conference, Nashville, Tennessee.

Dagrou, E., Gauvin, L., \& Halliwell, W. (1991). La préparation mentale des athlètes ivoiriens. Pratiques courantes et perspectives de recherche. [Mental preparation for Ivory Coast athletes. Current practice and research perspective]. International Journal of Sport Psychology, 22, 15-34.

Dale, G. A. (2000). Distractions and coping strategies of elite decathletes during their most memorable performances. The Sport Psychologist, 14, 17-41.

D'Arripe-Longueville, F., Fournier, J. F., \& Dubois, A. (1998). The perceived effectiveness of interactions between expert French judo coaches and female elite athletes. The Sport Psychologist, 12, 317-332.

D'Arripe-Longueville, F., Saury, J., Fournier, J., \& Durand, M. (2001). Coach-athlete interaction during elite archery competitions: An application of methodological frameworks used in ergonomics research to sport psychology. Journal of Applied Sport Psychology, 13, 275-

Defrancesco, C., \& Burk, K.L. (1997). Performance enhancement strategies used in a professional tennis tournament. International Journal of Sport Psychology, 18, 185-195.

Duda, J.L., \& Gano-Overway, L. (1996). Anxiety in elite young gymnasts: Part II-Sources of stress. Technique, 6, 4-5.

Durand-Bush, N., Salmela, J.H., \& Green-Demers, I. (2001). The Ottawa Mental Skills Assessment Tool (OMSAT-3). The Sport Psychologist, 15, 1-19.

Eklund, R.C., Gould, D., \& Jackson, S.A. (1993). Psychological foundations of olympic wrestling excellence: Reconciling individual differences and nomothetic characterization. Journal of Applied Sport Psychology, 5, 35-47.
Ericsson, K. A. Krampe, R. . \& Tesch-Romer. C. (1993). The role of deliberate practice in the acquisition of expert performance. Psychological Review, 100, 363-406.

Ericsson, K.A., \& Simon, H.A. (1993). Protocol analysis: Verbal reports as data. Cambridge, MA: MIT Press.

Garza, D.L., \& Feltz, D.L. (1998). Effects of selected mental practice on performance, selfefficacy, and competition confidence of figure skaters. The Sport Psychologist, 12, 1-15.

Gould, D. (2001, September). The psychology of Olympic excellence and it's development. Paper presented at the International Society of Sport Psychology Conference, Skiatos, Greece.

Gould, D., Dieffenbach, K., \& Moffett, A. (2002). Psychological talent and its development in Olympic champions. Journal of Applied Sport Psychology, 14, 172-204.

Gould, D., Eklund, R.C., \& Jackson, S.A. (1992a). 1988 U.S. Olympic wrestling excellence: I. Mental preparation, precompetitive cognition, and affect. The Sport Psychologist, 6, 358382.

Gould, D., Eklund, R.C., \& Jackson, S. A. (1992b). 1988 U.S. Olympic wrestling excellence:II. Thoughts and affect occurring during competition. The Sport Psychologist, 6, 383-402.

Gould, D., Guinan, D., Greenleaf, C., Medbery, R., \& Peterson, K. (1999). Factors affecting Olympic performance: Perceptions of athletes and coaches from more and less successful eams. The Sport Psychologist, 13, 371-394.

Gould, D., Tammen, V., Murphy, S., \& May, J. (1989). An examination of U.S. Olympic sport psychology consultants and the service they provide. The Sport Psychologist, 3, 300-312.

Grovios, G. (1992) . The effect of mental practice on diving performance. International Journal of Sport Psychologist, 23, 60-69.

Hanton, S., \& Jones, G. (1999). The acquisition and development of cognitive skills and strategies: I. Making the butterflies fly in formation. The Sport Psychologist, 13, 1-21.

Hardy, J., Gammage, K., Hall, C. (2001). A descriptive study of athlete self-talk. The Sport Psychologist, 15, 306-318.

Hollander, D. B., \& Acevedo, E. O. (2000). Successful English channel swimming: The peak experience.The Sport Psychologist, 14, 1-16.

Jackson, S.A. (1992). Athletes in flow: A qualitative investigation of flow states in elite figure skaters. Journal of Applied Sport Psychology, 4, 161-180.

Jackson, S. A., Dover, J., \& Mayocchi, L. (1998). Life after winning gold: I. Experiences of Australian Olympic gold medalists. The Sport Psychologist, 12, 119-136.

Jones, L., \& Stuth, G. (1997). The uses of mental imagery in athletics: An overview. Applied and Preventive Psychology, 6, 101-115.

Kendall, G., Hrycaiko, D., Martin, G.L., \& Kendall, T. (1990). The effect of an imagery rehearsal, relaxation, and self-talk package on basketball performance. Journal of Sport and Exercise Psychology, 12, 157-166. 
Krane, V. Greenleaf, C.A. \& Snow, J. (1997). Reaching for gold and the price of glory: A motivational case study of an elite gymnast. The Sport Psychologist, 11, 53-71.

Lincoln, Y.S., \& Guba, E.G. (1985). Naturalistic inquiry. Newbury Park, CA: Sage.

Li-Wei, Z., Qi-Wei, M., Orlick, T., \& Zitzelsberger, L. (1992). The effect of mental-imagery training on performance enhancement with 7-10 year-old children. The Sport Psychologist, 6. 230-241

Madigan, R., Frey, R.D., \& Matlock, T.S. (1992). Cognitive strategies of university athletes, Canadian Journal of Sport Sciences, 17, 135-140.

Magyar, T.M., \& Chase, M.A. (1996). Psychological strategies used by competitive gymnasts to overcome the fear of injury. Technique, 16, 25-27.

Mahoney, M.J., \& Avener, M. (1977). Psychology of the elite athlete: An exploratory study. Cognitive Therapy and Research, 1, 135-142.

Martin, K.A., Moritz, S.E., \& Hall, C.R. (1999). Imagery use in sport: A literature review and applied model. The Sport Psychologist, 13, 245-268.

Masters, K.S., \& Ogles, B.M. (1998). Associative and dissociative cognitive strategies in exercise and running: 20 years later, what do we know? The Sport Psychologist, 12, 253270

McCaffrey, N., \& Orlick, T. (1989). Mental factors related to excellence among top professional golfers. International Journal of Sport Psychology, 20, 256-278.

McPherson, S.L. (2000). Expert-novice differences in planning strategies during collegiate singles tennis competition. Journal of Sport \& Exercise Psychology, 22, 39-62.

Nicholls, J.G. (1989). The competitive ethos and democratic education. Cambridge, MA: Harvard University Press.

Orlick, T. (2000). In pursuit of excellence: How to win in sport and life through mental training. Champaign, L: Human Kinetics.

Orlick, T., \& Partington, J. (1988). Mental links to excellence. The Sport Psychologist, 2, 10530

Patton, M.Q. (1990). Qualitative evaluation and research methods. London:Sage Publications.

Rodgers, W., Hall, C., \& Buckolz, E. (1991). The effect of an imagery training program on imagery ability, imagery use, and figure skating performance. Journal of Applied Sport Psychology, 3, 109-125.

Rosenfeld, L.B., Richman, J.M., \& Hardy, C. J. (1989). Examining social support networks among athletes: Description and relationship to stress. The Sport Psychologist, 3, 23-33.

Rubin, H.J., \& Rubin, I.S. (1995). Qualitative interviewing: The art of hearing data. Thousand Oaks, CA:Sage.

Rushall, B. (1984). The content of competition thinking. In W. Straub \& J. Williams (Eds.) Cognitive sport psychology (pp. 51-62). New York: Sport Science Associates.
Rushall, B.S. \& Lippman, L.G. (1998). The role of imagery in physical performance. International Journal of Sport Psychology, 29, 57-72.

Savoy, C. (1997). Two individualized mental training programs for a team sport. International Journal of Sport Psychology, 28, 259-270.

Scanlan, T.K.,Stein, G.L., \& Ravizza, K. (1991). An in-depth study of former figure skaters: Part III. Sources of stress. Journal of Sport \& Exercise Psychology, 13, 103-120.

Strauss, A., \& Corbin, J. (1990). Basics of qualitative research: Grounded theory procedures and techniques. Newbury Park, CA: Sage.

Taylor, J. (1995). A conceptual model for integrating athletes' needs and sport demands in the development of competitive mental preparation strategies. The Sport Psychologist 9, 339357.

Terry, P.C., Mayer, J.L \& Howe, B.H. (1998). Effectiveness of a mental training program for novice scuba divers. Journal of Applied Sport Psychology, 10, 251-267.

Tesch, R. (1990). Qualitative research analysis types and software tools. New York: Falmer Press.

Thomas, P.R., Murphy, S.M., \& Hardy, L. (1999). Test of performance strategies: Development and preliminary validation of a comprehensive measure of athletes' psychological skills. Journal of Sports Sciences, 17, 697-711.

Vealey, R.S. (1988). Future directions in psychological skills training. The Sport Psychologist, 2 318-336.

Vealey, R.S. (1994). Current status and prominent issues in sport psychology interventions. Medicine and Science in Sports and Exercise 26, 495-502.

Vergeer, I., \& Hanrahan, C. (1998). What modern dancers do to prepare: Content and objectives of preperformance routines. Avante, 4, 49-71.

Von Cranach, M., \& Harré, R. (Eds.). (1982). The analysis of action: Recent theoretical and empirical advances. Cambridge: University Press.

Weinberg, R., \& Comar, W. (1994). The effectiveness of psychological interventions in competitive sports. Sport Medicine, 18, 406-418.

Weiss, M.R. (1991). Psychological skill development in children and adolescents. The Sport Psychologist, 5, 335-354

White, S.A., \& Duda, J.L. (1994). The relationship of gender, level of sport involvement, and participation motivation to task and ego orientation. International Journal of Sport Psychology, 25, 4-18.

Williams, J.M., \& Krane, V. (1998). Psychological characteristics of peak performance. In J.M. Williams (Ed.), Applied sport psychology: Personal growth to peak performance (pp.158170). Mountain View, California: Mayfield Publishing Company. 
The authors are grateful to the athletes who participated in the study, and would also like to thankK Anders Ericsson for his helpfulcomments on earlierversions of this article Pattof paperwas presented ath of Applied Sport Psychology, Nashville, USA

\section{ApPendix: Program of the PST}

The 25 sessions of the PST program consisted in learning the following basic skills: (a) relaxation, (b) self-talk, (c) goal setting, (d) focusing, and (e) imagery.

Relaxation training was composed of eight sessions where the gymnasts were introduced to: (a) an awareness of normal abdominal breathing, (b) a muscular relaxation from head to toes with the evocation of a "mental picture", and (c) a simplified version of the Jacobson progressive relaxation. Relaxation was presented as a way of controlling emotions.

Self-talk was identified, transformed from negative to positive, and used during

training. It was delivered during five sessions and was presented as a way of coping with the fear of producing a new acrobatic skill without spotting and of refocusing after making a mistake or falling during a competition.

Goal setting was presented during three sessions. Gymnasts were taught the purpose of setting goals, the distinction between final andintermediate goals, and outcome and

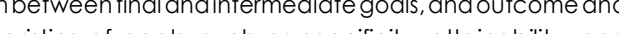
mastery of goals. charactistics of goals, such as specificly, attainabilly, and emphasized.

Focusing consisted of four sessions. Gymnasts learned to focus on one thing (breathing, object, sound, thought, emotion) and to shift their focus between a large and narrow external focus, between objects, thoughts, and emotions. Applied exercises were suggested, such as the simulation of a fall and the refocusing on positive thoughts.

The program on imagery was made up of five sessions, in which gymnasts learned to use external and internal imagery. The visualization from an external perspective was done with or without the help of drawings of the entire routine or part of it. Imaging the major difficulty from an internal perspective, both halves of the routine, or the entire routine, was done mainly by associating the kinesthetic modality. All these imagery exercises were completed first in a calm place, and then in the training gymnasium. 